\title{
Performance Improvement of Nano-silica/Polypropylene Composites through in-situ Graft Modification of Nanoparticles during Melt Compounding
}

\author{
Tong Hui Zhou, ${ }^{1,2}$ Wen Hong Ruan, ${ }^{3}$ * Yue Lin Wang, ${ }^{4}$ Yu Liang Mai, ${ }^{2}$ Min Zhi Rong, ${ }^{3}$ \\ Ming Qiu Zhang ${ }^{3}$
}

${ }^{1}$ Key Laboratory for Polymeric Composite and Functional Materials of Ministry of Education, Zhongshan University, Guangzhou 510275, P. R. China; 86-20-84114008; zhoutonghui@126.com

${ }^{2}$ Guangdong Public Laboratory of Chemical Engineering, Guangzhou 510665, P. R. China; 86-20-84114008; zhoutonghui@126.com

${ }^{3}$ Materials Science Institute, Zhongshan University, Guangzhou 510275, P. R. China; 86-20-84114008; cesrwh@mail.sysu.edu.cn, cesrmz@zsu.edu.cn, ceszmq@zsu.edu. $\mathrm{cn}$

${ }^{4}$ Guangzhou GBS High-Tech \& Industry Co., Ltd., \#623 Sha Tai Nan Rd., Guangzhou 510510, P. R. China

* Materials Science Institute, Zhongshan University, Guangzhou 510275, P. R. China; Fax number: 86-20-84114008; Email: cesrwh@mail.sysu.edu.cn

(Received: 15 December, 2006; published: 30 May, 2007)

\begin{abstract}
To prepare inorganic nanoparticles filled polymer composites, reactive monomer was added to the ingredients prior to manufacturing. The results showed that in-situ graft polymerization of butyl acrylate onto nano-silica occurred during melt compounding with polypropylene matrix. As a result, dispersion of the grafted nanoparticles in the polymer became much more homogeneous than in the case of untreated version, and filler/matrix interaction was enhanced due to the intimate adhesion among the components. Both tensile performance and impact toughness of the composites were improved at rather low filler loading. Compared to the twostep approach developed in our lab, by which nanoparticles are treated by graft polymerization firstly and then mixed with polymer melt, the current one-step method is simpler and able to provide the composites with much higher notched impact resistance.
\end{abstract}

\section{Introduction}

Addition of nanoscopic powders into polymers is an attractive topic for plastics industry, because the nanocomposites exhibit a wide range of enhanced performance, such as mechanical, thermal and tribological properties, at relatively low filler loading [1, 2]. However, homogeneous dispersion of nanoparticles in a polymer matrix is very difficult because nanoparticles tend to agglomerate during melt compounding $[3,4]$. The loosened nanoparticle agglomerates embedded in polymers would result in properties of the composites even worse than those of micrometersized fillers systems.

To improve dispersibility of the nano-fillers in polymeric matrices, maleic anhydride grafted polypropylene (PP) was used as a compatibilizer [5-7]. The hydroxyl of silica 
nanoparticles or clay could react with maleic anhydride groups to well disperse the nano-fillers within matrix polymer through in-situ compatibilization. Comparatively, the organo-treated nanoparticles were dispersed more effectively than the untreated ones [7]. In fact, surface treatment of nanoparticles is an important measure. Compared to coupling agent encapsulation, graft polymerization onto nanoparticles has many advantages [8, 9], like (i) low molecular weight grafting monomers can easily penetrate into nanoparticle agglomerates and react with the interior and exterior particulates to break up the agglomerates, (ii) filler/matrix interaction would be enhanced by interdiffusion and entanglement between the grafted polymers and the matrix, and (iii) interfacial interaction can be tailored by changing species of grafting monomers and graft conditions. Our previous work demonstrated that incorporation of irradiation grafted inorganic nanoparticles into PP brought about substantial toughening and strengthening effects [10]. On this basis, recently some technical routes were developed in our laboratory. For instance, a polymerizable foaming agent was grafted onto nano-silica to promote dispersion of the nanoparticles in PP through in-situ chemical blowing [11, 12]. Besides, polymer chains possessing reactive epoxide groups were grafted onto nano-silica [13]. When the modified nanoparticles were melt compounded with aminated PP, reaction between epoxide groups of the grafting polymers and amine groups of the functional PP took place so that nano-silica was covalently bonded to the matrix.

So far, graft polymerization on particulate surface is mostly carried out in solution via various chemical processes [10-14]. It is not environmentally friendly enough and not cost effective in view of large-scale production. In addition, some compact agglomerates consisting of the nanoparticles, grafted polymer and ungrafted polymer are still hard to be split when the grafted nanoparticles are mixed with polymer melt, which might be responsible for the high notch sensitivity of the composites. To solve the problem generated by the aforesaid two-step approach, a simplified one-step strategy is adopted in this work. That is, nanoparticles are pretreated by silane coupling agent to introduce reactive $\mathrm{C}=\mathrm{C}$ double bonds onto the surface. Afterwards, mixture of the silane pre-treated nanoparticles, graft monomer, initiator and matrix polymer is melt compounded. The graft monomer is expected to react with silane coupling agent on the nanoparticles and then to form grafted macromolecules in-situ in the course of compounding. As a result of side reaction, slight graft polymerization on the matrix polymer might take place. Nevertheless, it should be an effective way to eliminate agglomeration of nanoparticles and improve intimate interaction between the nano-fillers and matrix.

The present paper reports results of the above idea. Silica nanoparticles serves as the filler, which is in-situ modified by grafting butyl acrylate (BA) onto their surfaces during melt mixing with PP. The influence of processing conditions on mechanical performance of the resultant nano-silica/PP composites is investigated. In addition, crystalline characteristics, dynamic mechanical property and morphology of the PP composites are studied to reveal the mechanism accounting for the performance enhancement.

\section{Results and discussion}

\section{In-situ graft polymerization during melt compounding}

Considering that graft polymerization onto nanoparticulate surfaces in molten PP is more difficult than in solution of the polymer, two measures were taken to increase 
reactivity of the system. First, nano-silica was pretreated by the silane coupling agent, $\mathrm{Y}$-methacryloxypropyl trimethoxy silane, to introduce double bonds onto surface of the nanoparticles [15] (for the convenience of discussion, $6.62 \mathrm{wt} \%$ coupling agent attached to nano-silica surface, as determined by thermogravimetric analysis (TGA), is fixed in the subsequent study).

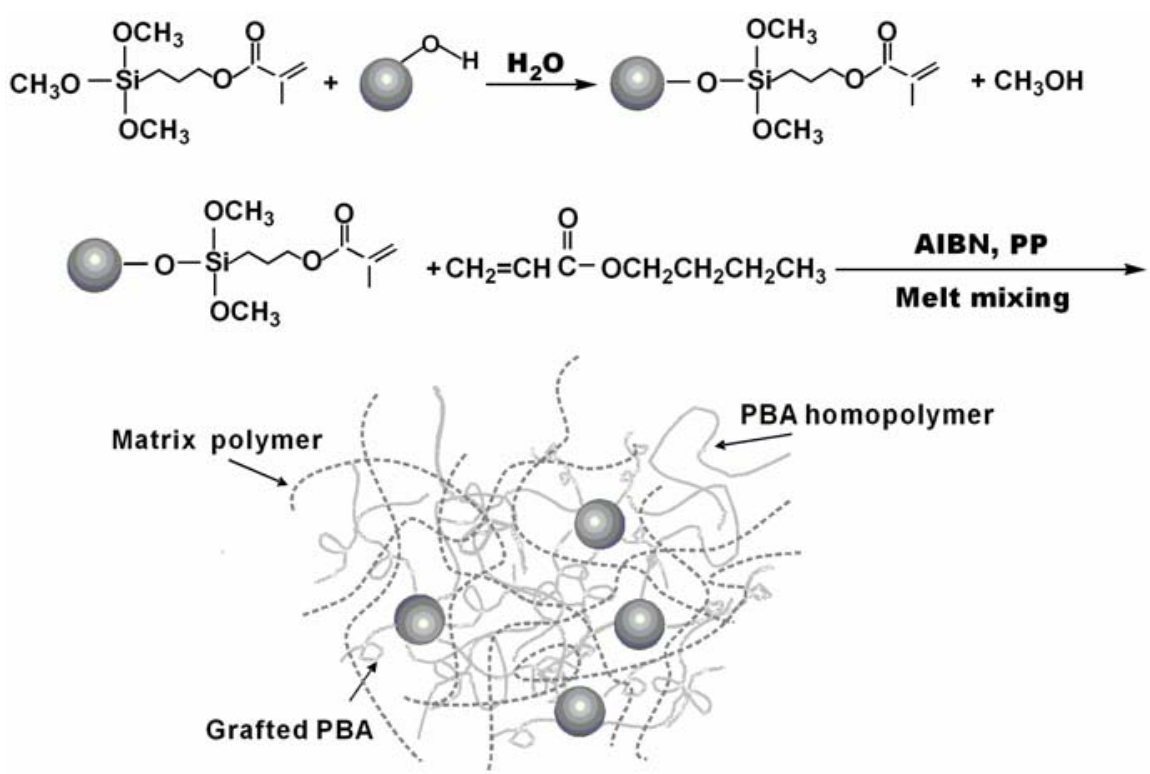

Fig. 1. Schematic drawing of the principle of in-situ grafting modification of nanosilica [15].

Second, concentrated batches were made by incorporating nano-silica and graft monomer into the matrix so as to increase collision between nano-silica and the monomer under melt mixing. Then, the concentrated batches were diluted into desired concentrations to prepare nano-silica/PP composites. A schematic drawing of the in-situ grafting modification of nano-silica is shown in Figure 1.

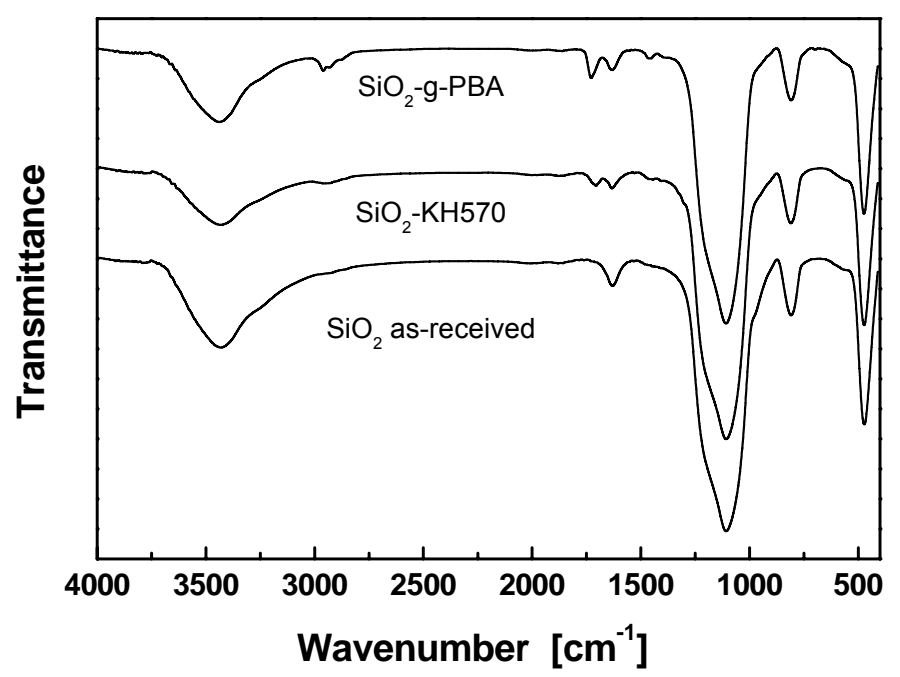

Fig. 2. FTIR spectra of nano-SiO 2 as-received, silane treated nano-SiO $\mathrm{KH} 570)$ and nano-SiO ${ }_{2}$ extracted from the composites $\left(\mathrm{SiO}_{2}-\mathrm{g}-\mathrm{PBA}\right)$. 
Figure 2 gives the infrared spectra of the untreated nano-silica, KH570 treated nanosilica (denoted by $\mathrm{SiO}_{2}-\mathrm{KH} 570$ ) and the grafted nano-silica (which was obtained by removing $\mathrm{PP}$ and ungrafted $\mathrm{PBA}$ in the composites via solvent extraction, denoted by $\mathrm{SiO}_{2}-\mathrm{g}-\mathrm{PBA}$ ). In comparison with the spectrum of nano-silica as-received, the adsorption peak at $1704 \mathrm{~cm}^{-1}$ in the spectrum of $\mathrm{SiO}_{2}-\mathrm{KH} 570$ indicates appearance of carbonyl groups. The result suggests that double bonds have been introduced onto surface of nanoparticles. Owing to formation of hydrogen bonding between carbonyl groups of the coupling agent and the silanol groups of silica, the carbonyl groups have to absorb at a lower wavenumber than that of neat KH570 [15]. In the spectrum of grafted nano-silica, the carbonyl peak shifts back to $1729.3 \mathrm{~cm}^{-1}$, manifesting that double bonds of $\mathrm{SiO}_{2}-\mathrm{KH} 570$ have reacted with reactive monomer and PBA has been chemically grafted onto the nano-silica during melt compounding [15]. In addition, appearance of the weak peak at $2965 \mathrm{~cm}^{-1}$, which should be related with methyl and methylene groups, implies that some side reactions of the matrix, such as slight crosslinking of PP, might have taken place in the meantime. This would also be beneficial for the filler/matrix interaction.

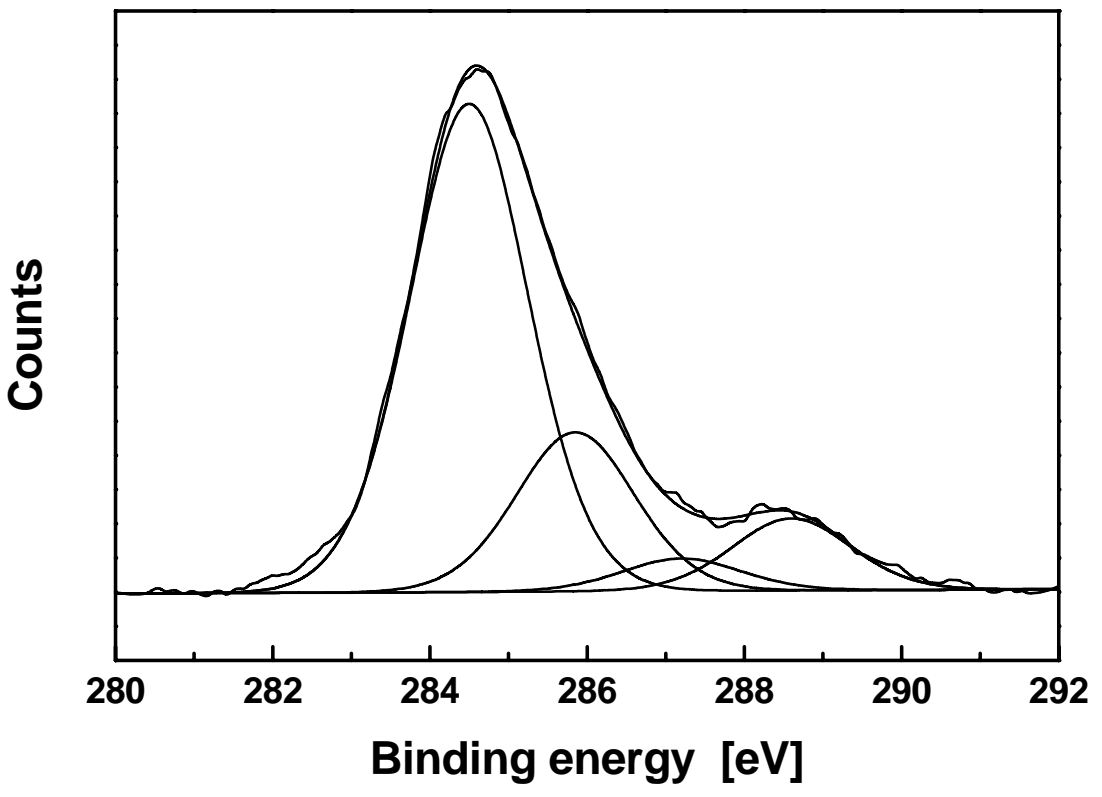

Fig. 3. $\mathrm{C} 1 \mathrm{~s}$ spectrum of $\mathrm{SiO}_{2}-\mathrm{g}-\mathrm{PBA}$ with peak deconvolutions.

To further confirm existence of the grafted polymer on the nanoparticles, XPS spectra of $\mathrm{SiO}_{2}$-g-PBA were collected. As shown by the $\mathrm{C} 1 \mathrm{~s}$ spectrum in Figure 3, the peaks at $284.5,285.8,287.2$ and $288.6 \mathrm{eV}$ represent $\mathrm{C}-\mathrm{C}$ or $\mathrm{C}-\mathrm{H}, \mathrm{C}-\mathrm{OH}, \mathrm{O}=\mathrm{C}-\mathrm{O}-$, respectively. That is, the $\mathrm{C} 1 \mathrm{~s}$ spectrum of $\mathrm{SiO}_{2}-\mathrm{g}-\mathrm{PBA}$ is similar to that of neat PBA, and no new binding energy of $\mathrm{C}$ element is observed. It proves that PBA has been grafted on the surface of $\mathrm{SiO}_{2}$ via $\mathrm{C}=\mathrm{C}$ double bonds. Si2p spectra of $\mathrm{SiO}_{2}-\mathrm{KH} 570$ and $\mathrm{SiO}_{2}$-g-PBA (Figure 4) also give a clue, in which the $\mathrm{Si} 2 \mathrm{p}$ peak of $\mathrm{SiO}_{2}$-g-PBA moves towards lower binding energy and its intensity becomes weaker than that of $\mathrm{SiO}_{2}-\mathrm{KH} 570$. It reveals that some of silicon atoms become electron-poorer when PBA was grafted on nano-silica, as the ether oxygen atom of the grafted PBA has a strong electron-withdrawing effect. Proportion of the elements on the surface of nano-silica can be determined by the relative intensity of the peaks in XPS spectra (Table 1). 
Theoretically, the ratio of $\mathrm{O}$ to $\mathrm{Si}$ of untreated $\mathrm{SiO}_{2}$ ought to be less than 2, and $\mathrm{C}$ element should not be perceived. In fact, the experimental data in Table 1 demonstrate that the ratio of $\mathrm{O}$ to $\mathrm{Si}$ of untreated $\mathrm{SiO}_{2}$ is slightly higher than 2, while small amount of $\mathrm{C}$ element is detected $(\mathrm{C} / \mathrm{Si}=0.15)$. With high surface activity, nanosilica is apt to absorb a small quantity of water forming hydrogen bonds. This leads to the increase in oxygen content of nano-silica. Meanwhile, the surfaces of industrial nano-silica always have a few of carbon-contaminant. As for $\mathrm{SiO}_{2}-\mathrm{KH} 570$, the proportions of $\mathrm{C}$ to $\mathrm{Si}$ and $\mathrm{O}$ to $\mathrm{Si}$ are higher than those of untreated nano-silica because the silane coupling agent has plenty of carbon atoms and high $\mathrm{O} / \mathrm{Si}$ ratio. Compared to the case of $\mathrm{SiO}_{2}-\mathrm{KH} 570, \mathrm{O} / \mathrm{Si}$ and $\mathrm{C} / \mathrm{Si}$ ratios of $\mathrm{SiO}_{2}-\mathrm{g}-\mathrm{PBA}$ increase further. It proves the effect of in-situ graft polymerization, which brought many $\mathrm{O}$ and $\mathrm{C}$ atoms onto the surface of nano-silica.

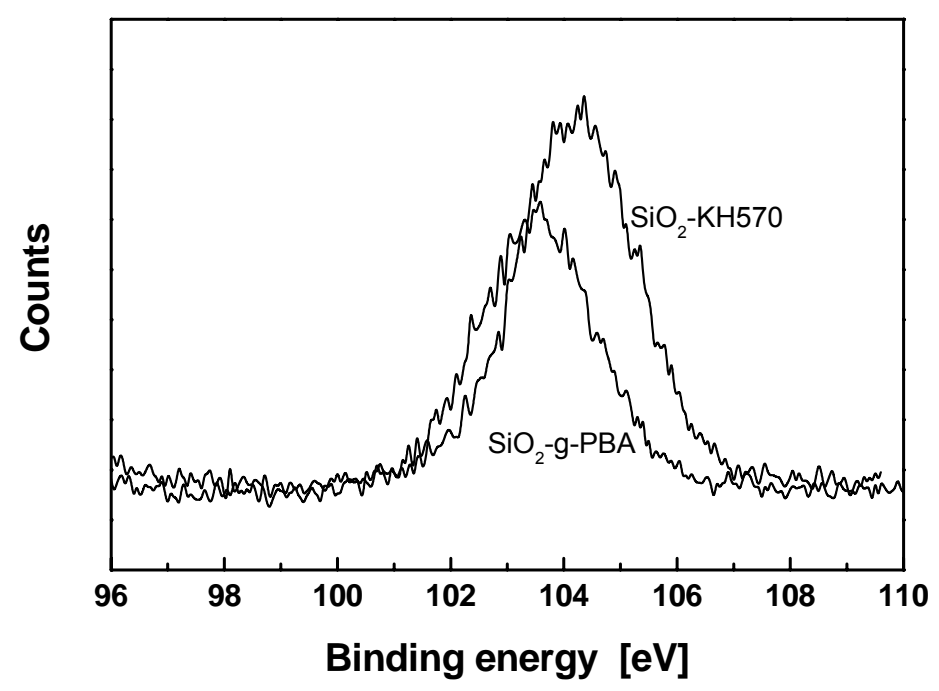

Fig. 4. Si2p spectra of $\mathrm{SiO}_{2}-\mathrm{KH} 570$ and $\mathrm{SiO}_{2}-\mathrm{g}-\mathrm{PBA}$

Tab. 1. XPS peak area ratios yielded from $\mathrm{Si} 2 \mathrm{p}, \mathrm{O} 1 \mathrm{~s}$ and $\mathrm{C} 1 \mathrm{~s}$ spectra of untreated and treated nano- $\mathrm{SiO}_{2}$.

\begin{tabular}{cccc}
\hline Materials & $\mathrm{SiO}_{2}$ as-received & $\mathrm{SiO}_{2}-\mathrm{KH} 570$ & $\mathrm{SiO}_{2}-\mathrm{g}-\mathrm{PBA}$ \\
\hline $\mathrm{Si}: \mathrm{O}: \mathrm{C}$ & $1: 2.02: 0.15$ & $1: 2.34: 2.45$ & $1: 2.49: 3.28$ \\
\hline
\end{tabular}

Influence of filler content and processing conditions on mechanical properties of nano-silica/PP nanocomposites

Changing concentrations of monomer and initiator, and melt compounding conditions, concentrated batches with different monomer conversions and percent grafting have been obtained. Hereinafter, the concentrated batch with monomer conversion of $77.0 \%$, and percent grafting of $15.91 \%$, as detected by TGA, is chosen for manufacturing the composites to be studied. As stated above, for preparing nano-silica/PP composites, the concentrated batch has to be diluted into desired concentrations. Suitable silica concentration is critical because the content of nanoparticles is related to their dispersion status in matrix and influences the ratio of mechanical properties to cost of the nanocomposites. 
Figure 5 shows the mechanical properties of the resultant nanocomposites as a function of nano-silica content. Compared to the untreated version, addition of $\mathrm{SiO}_{2}-$ g-PBA can significantly improve notched Charpy impact strength of PP over the entire range of filler loading of interests (Figure 5(a)). Besides, tensile strength and Young's modulus of the composites are also increased (Figure 5(b) and (c)), despite the fact that the tensile strength starts to decrease at certain nano-silica content due to the deteriorated dispersion of the particles. The reinforcing and toughening effect should result from the grafted nano-silica instead of flexible PBA, since incorporation of pure PBA into PP would remarkably reduce tensile strength and modulus of the matrix except for a slight increase in toughness.

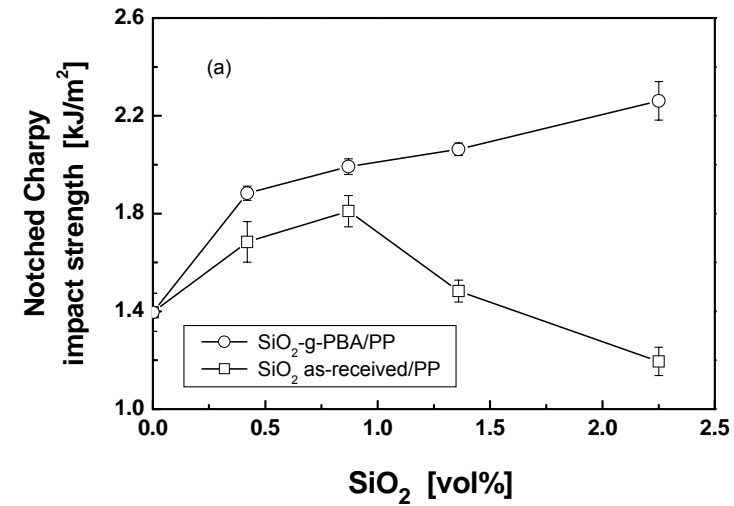

(a)

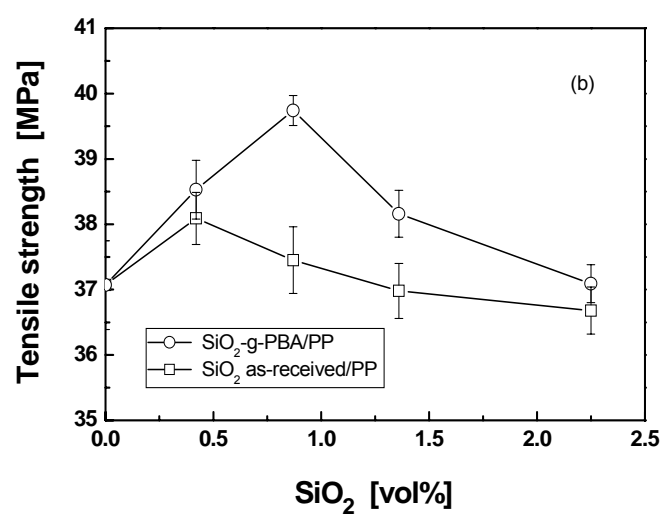

(b)

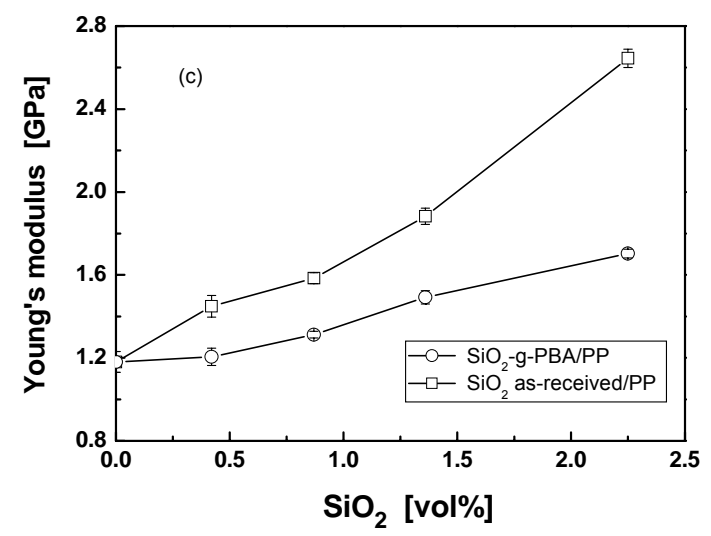

(c)

Fig. 5. Mechanical properties of PP composites as a function of nano-silica volume fraction: (a) Notched Charpy impact strength, (b) tensile strength, and (c) Young's modulus.

In our previous works [10-13], two-step procedure was adopted to prepare nanocomposites. That is, nano-silica was grafted in advance, and then melt compounded with matrix PP. Although strength and ductility of the composites were greatly enhanced, improvement of notch impact strength was insignificant. In this context, the results given in Figure 5(a) illustrate that the aforesaid main open problem has been solved without losing the strengthening and stiffening effects by taking advantages of the one-step strategy developed in the present work. The in-situ formed grafted nanoparticles must have been tightly adhered to the matrix PP and provide increased resistance against crack propagation. 
To dilute concentrated batch into desired concentrations, a mixer of Haake torque rheometer was used. Therefore, processing conditions of the mixer should be studied. As shown in Figure 6, notched impact strength and tensile strength of the nanocomposites decrease with increasing mixing temperature and have an optimum value with a rise in rotation speed and mixing time, and fluctuate with rotation speed more severely than with mixing temperature and time. In fact, PP is more sensitive to shear rate so that an acceleration of rotation speed would effectively decrease its melt viscosity, but elevated temperature tends to cause degradation of PP. Decrease of melt viscosity is desirable to improve nanoparticles dispersion in matrix.
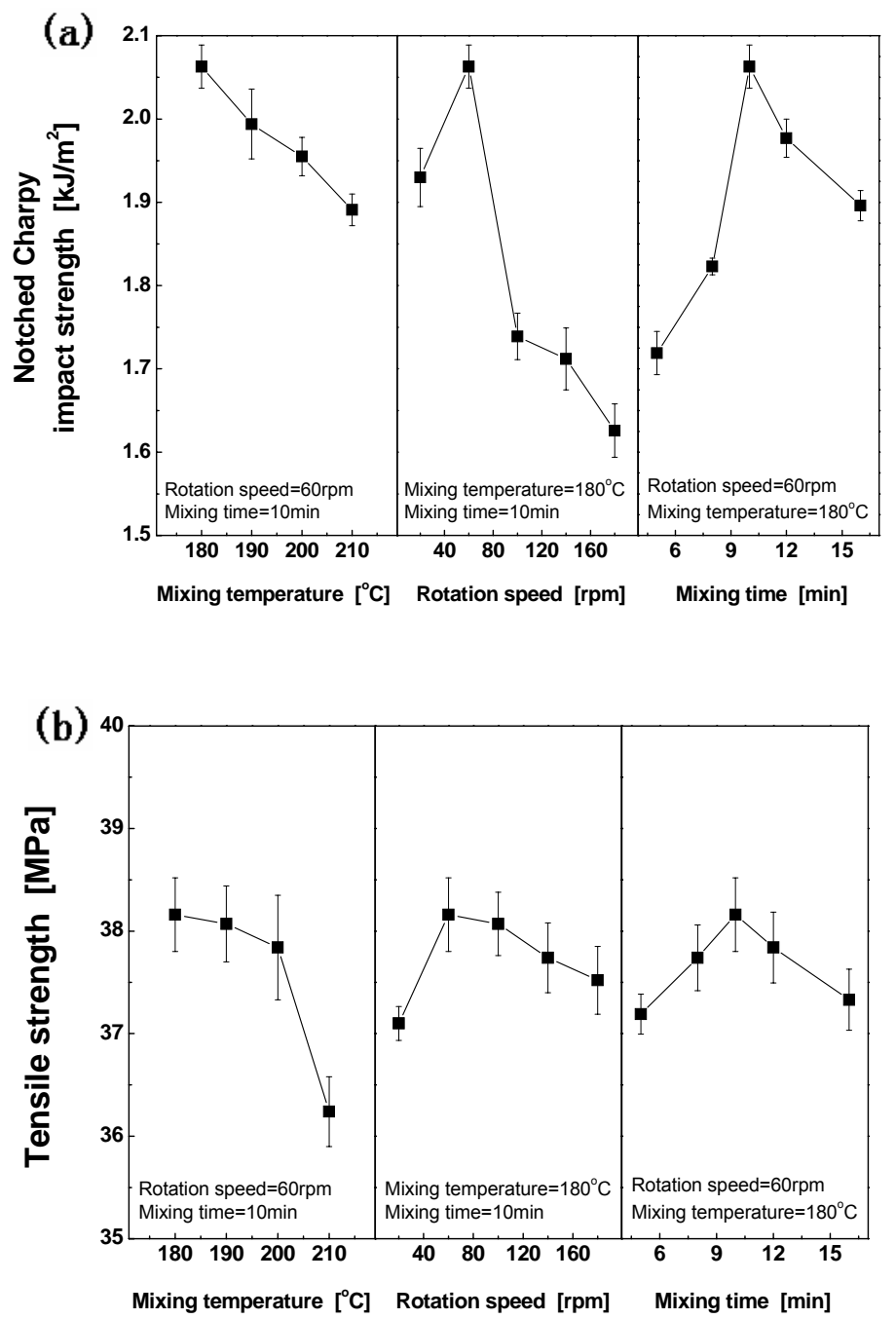

Fig. 6. (a) Notched Charpy impact strength and (b) tensile strength of PP composites as a function of mixing temperature, rotation speed and mixing time of the mixer. Content of nano-SiO ${ }_{2}=1.36 \mathrm{vol} \%$.

Nevertheless, an increase in rotation speed and mixing time might also lead to matrix degradation. As a result, mechanical properties of the nanocomposites change as a function of rotation speed and mixing time, having an optimum value. To balance mechanical properties and energy consumption, the reasonable melt mixing conditions can be set as $180^{\circ} \mathrm{C}, 10 \mathrm{~min}$ and $60 \mathrm{rpm}$. 
Crystalline characteristics and dynamic mechanical property

Table 2 collects the DSC studies of non-isothermal crystallization and melting behavior of PP and its nanocomposites. The data show that melting point of PP is nearly not affected by the nano-silica. It means that no transition of crystal form occurs, which coincides with the result of wide angle X-ray diffraction study. On the other hand, supercooling temperature, $\Delta T$, of the polymer decreases with the addition of untreated $\mathrm{SiO}_{2}$ and $\mathrm{SiO}_{2}-\mathrm{g}-\mathrm{PBA}$, indicating that crystallization of the nanocomposites becomes easier owing to the nucleation effect of the nanoparticles. The $\mathrm{SiO}_{2}$-g-PBA/PP composites have lower $\Delta \mathrm{T}$ but higher crystallinity than $\mathrm{SiO}_{2} / \mathrm{PP}$. Some researchers $[16,17]$ suggested that particulate fillers influence crystallization behavior of polymer matrices not only because the fillers act as nucleation agents, but also the filler/matrix interfacial stress has effect.

Tab. 2. Non-isothermal crystallization and melting data of PP and its nano composites.

\begin{tabular}{|c|c|c|c|c|}
\hline Samples & $\mathrm{T}_{\mathrm{m}}{ }^{\mathrm{a}}\left({ }^{\circ} \mathrm{C}\right)$ & $\mathrm{T}_{\mathrm{c}}^{\mathrm{b}}\left({ }^{\circ} \mathrm{C}\right)$ & $\Delta \mathrm{T}^{\mathrm{C}}\left({ }^{\circ} \mathrm{C}\right)$ & $X_{c}^{d}(\%)$ \\
\hline Neat PP & 162.96 & 112.89 & 50.07 & 46.7 \\
\hline $\mathrm{SiO}_{2} / \mathrm{PP}$ & 162.92 & 118.39 & 44.53 & 44.9 \\
\hline $\begin{array}{c}\mathrm{SiO}_{2}-\mathrm{g}-\mathrm{PBA} / \mathrm{PP} \\
\text { (percent grafting }=11.76 \% \text { ) }\end{array}$ & 162.90 & 122.12 & 40.78 & 46.62 \\
\hline $\begin{array}{c}\mathrm{SiO}_{2}-\mathrm{g}-\mathrm{PBA} / \mathrm{PP} \\
\text { (percent grafting }=15.91 \% \text { ) }\end{array}$ & 161.76 & 122.21 & 39.55 & 45.53 \\
\hline $\begin{array}{l}{ }^{\mathrm{a}} \mathrm{T}_{\mathrm{m}} \text { : peak melting temperature } \\
{ }^{\mathrm{b}} \mathrm{T}_{\mathrm{c}}: \text { peak crystallization tempera } \\
{ }^{\mathrm{c}} \Delta \mathrm{T}=\mathrm{T}_{\mathrm{m}}-\mathrm{T}_{\mathrm{c}} \text {, denoting supercoo } \\
{ }^{\mathrm{d}} \mathrm{X}_{\mathrm{c}} \text { : matrix crystallinity } \\
{ }_{\text {Content of nano-SiO }}: 1.36 \mathrm{vol} \%\end{array}$ & tempera & & & \\
\hline
\end{tabular}

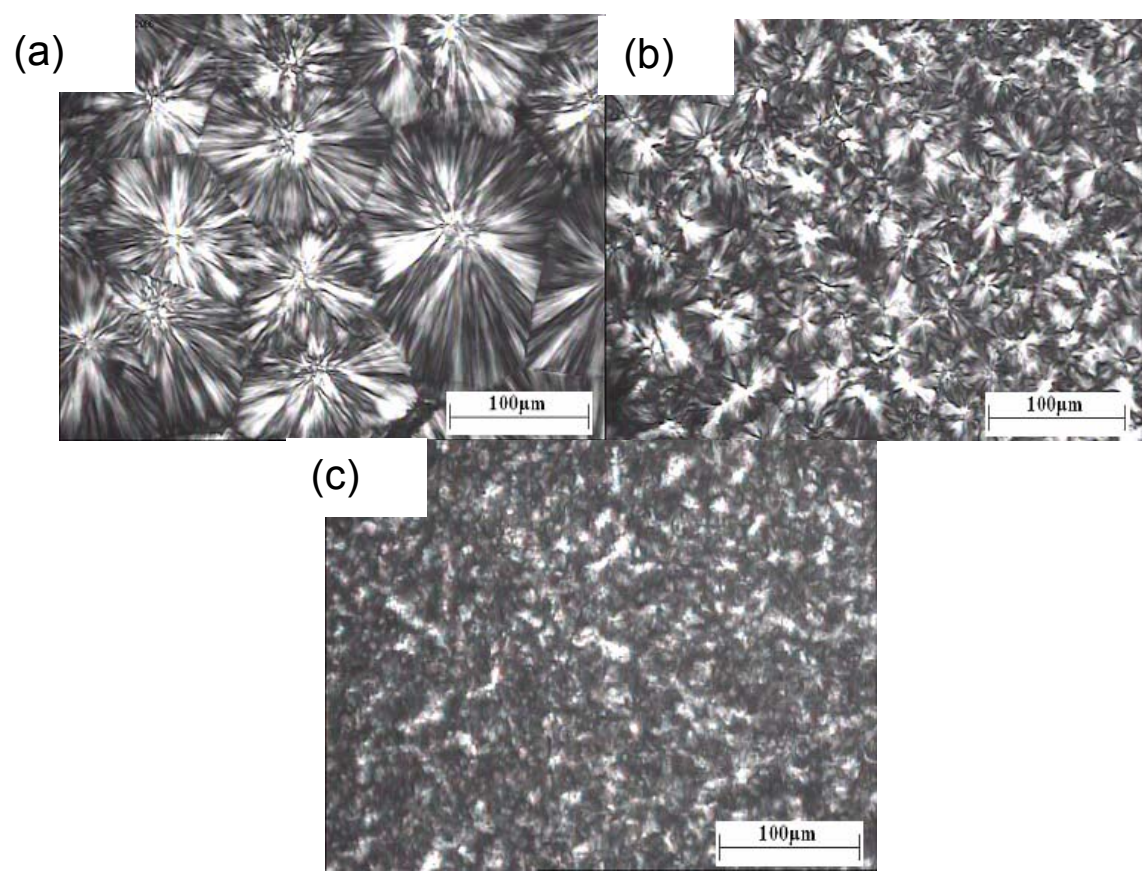

Fig. 7. Polarized light micrographs of (a) $\mathrm{PP}$, (b) $\mathrm{SiO}_{2}$-as-received/PP and (c) $\mathrm{SiO}_{2}-\mathrm{g}$ PBA/PP composites. Content of $\mathrm{SiO}_{2}=1.36$ vol $\%$. 
Uniformly dispersed fillers would produce higher interfacial stress accumulation and stronger interfacial bonding that ensures better interfacial stress transfer. Consequently, rate of crystallization and crystallinity of the composites with welldispersed fillers would be higher than those of the systems containing poorly dispersed fillers. According to their consideration, the data in Table 2 might evidence that $\mathrm{SiO}_{2}$-g-PBA/PP composites have more uniform particles dispersion and enhanced interfacial adhesion than the untreated silica system.

From polarized light micrographs in Figure 7(a), it is seen that crystalline morphology of PP is represented by typical spherulites [18]. The spherulites' size of $\mathrm{SiO}_{2} / \mathrm{PP}$ becomes smaller (Figure 7(b)) owing to nucleation effect of nano-silica. With respect to $\mathrm{SiO}_{2}$-g-PBA/PP, the spherulites boundaries become vague due to chain interdiffusion and entanglement between the grafted polymer and the matrix (Figure $7(c)$ ). Relating the crystalline morphology with the fact that there is little influence of nano-silica on crystallinity and melting point of matrix (see Table 2), the results give a hint that most nanoparticles might be distributed in the amorphous phase of the matrix, except for those acting as nucleation agents [19, 20].

For obtaining more information about amorphous phase of the composites, dynamic mechanical property of PP and its composites was tested (Figure 8, Table 3). The results show that incorporating untreated and grafted nano-silica into PP slightly decreases glass transition temperature of PP, and the storage moduli, E', of the composites are raised because the nanoparticles can impart high stiffness of the fillers to the matrix. The area under the peak of loss modulus of PP, $S_{l}$, is a parameter related to the degree of interaction between the phases [21]. Obviously,

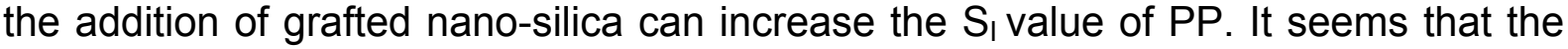
grafted nanoparticles play the role of physical crosslinking sites in the amorphous PP phase. Hence the composites consist of more effective components in which craze can be induced during fracture of the materials. In other words, the in-situ graft polymerization technique improves interaction between the nanoparticles and PP matrix, and incorporates reinforcement and toughening effects of the nanoparticles to PP.

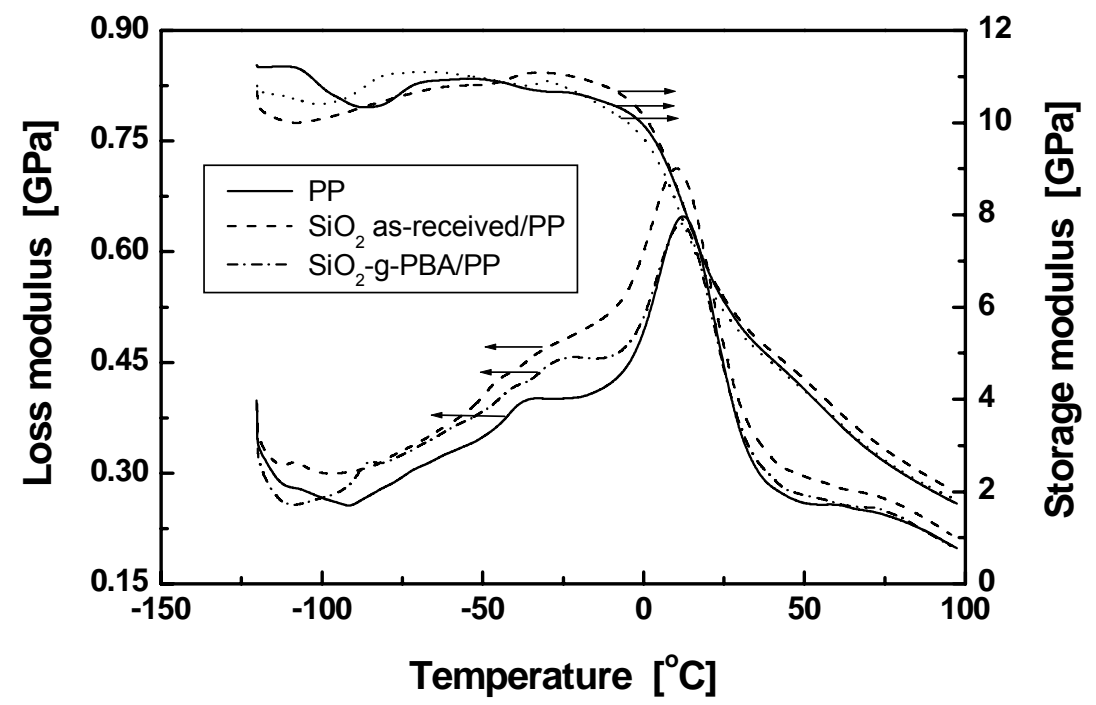

Fig. 8. Temperature dependence of storage modulus and loss modulus of PP and its nanocomposites measured at $1 \mathrm{~Hz}$. Content of $\mathrm{SiO}_{2}=1.36 \mathrm{vol} \%$. 
Tab. 3. Characteristic DMA parameters of PP and its nanocomposites in the glass transition region.

\begin{tabular}{|c|c|c|c|}
\hline Samples & $\mathrm{T}_{\mathrm{g}}\left({ }^{\circ} \mathrm{C}\right)$ & $E^{\prime}(\mathrm{GPa})$ & $\mathrm{S}_{\mathrm{I}}(\mathrm{MPa} \cdot \mathrm{min})$ \\
\hline PP & 16.29 & 10.41 & 6267.0 \\
\hline $\mathrm{SiO}_{2} / \mathrm{PP}$ & 15.45 & 11.06 & 6526.0 \\
\hline $\mathrm{SiO}_{2}-\mathrm{g}-\mathrm{PBA} / \mathrm{PP}$ & 15.03 & 11.75 & 7336.0 \\
\hline
\end{tabular}

Morphology of the nanocomposites

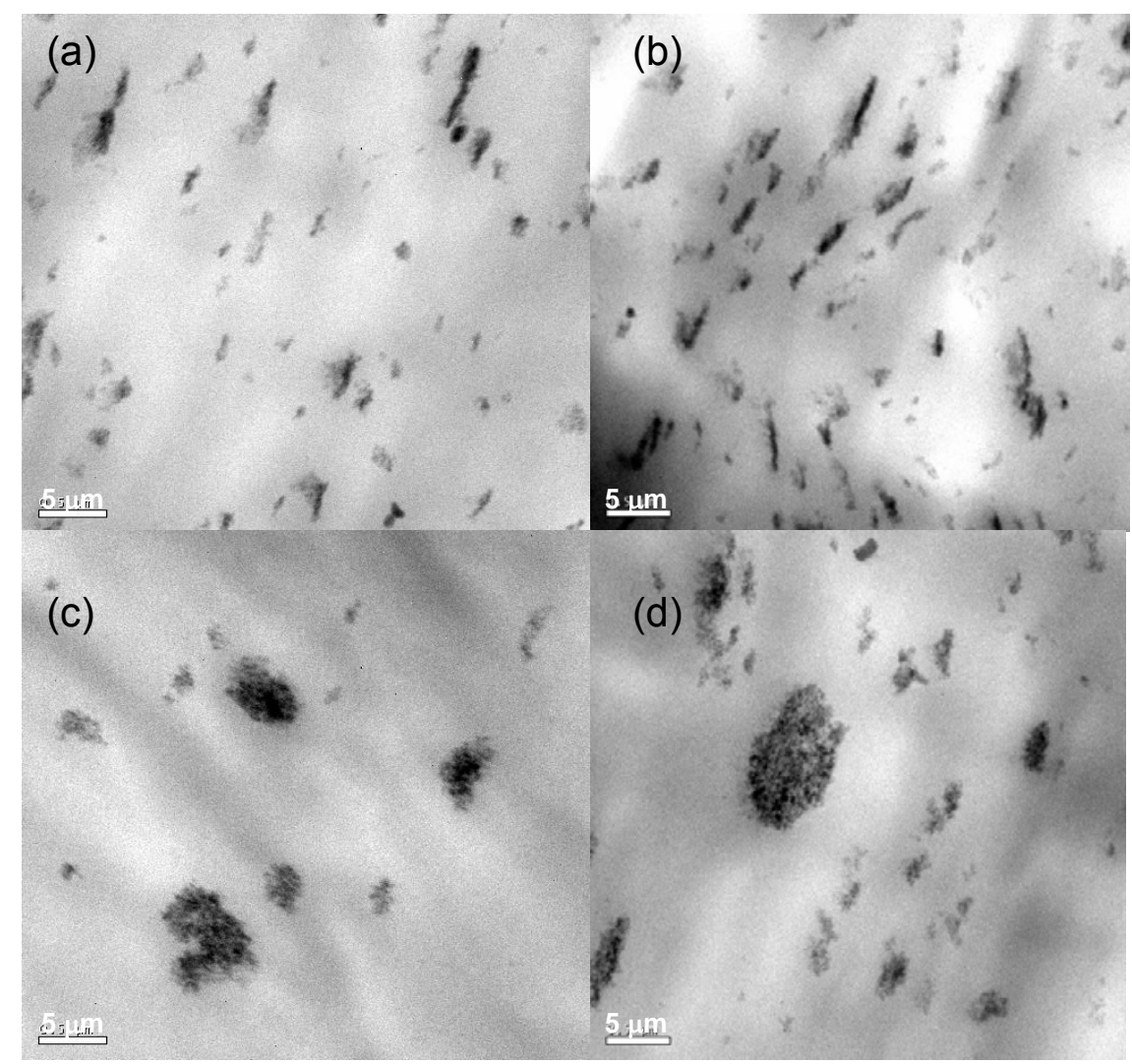

(c)

(d)

Fig. 9. TEM micrographs of $\mathrm{PP}$ based nanocomposites: (a) $\mathrm{SiO}_{2}-\mathrm{g}-\mathrm{PBA} / \mathrm{PP}$ perpendicular to the injection direction of impact bars, (b) $\mathrm{SiO}_{2}$-g-PBA/PP parallel to the injection direction of impact bars, (c) $\mathrm{SiO}_{2}$ as-received/PP perpendicular to the injection direction of impact bars, and (d) $\mathrm{SiO}_{2}$ as-received/PP parallel to the injection direction of impact bars. Content of $\mathrm{SiO}_{2}=1.36$ vol\%.

From TEM micrographs of the nanocomposites it can be seen that although some small agglomerates of nanoparticles are perceived, dispersion of the grafted nanosilica (Figure $9(a)$ ) is much more homogeneous than that of the untreated silica 
(Figure 9(c)). An interesting result lies in the "drawn pattern" of $\mathrm{SiO}_{2}$-g-PBA (Figure $9(a) \&(b))$, which were taken from the ultrathin sections cut perpendicular and parallel to the injection direction of impact bars, respectively. For $\mathrm{SiO}_{2} / \mathrm{PP}$, only roughly perceivable "drawn patterns" are found on the section cut along the injection direction (Figure 9(d)). Because of interdiffusion and entanglement between the grafted polymer and PP matrix, tiny $\mathrm{SiO}_{2}-\mathrm{g}-\mathrm{PBA}$ agglomerates can be deformed with injection-induced flow of the matrix to form "drawn patterns" at an angle with the injection direction.

SEM micrographs of impact fractured surfaces of the composites near the notch zone are illustrated in Figure 10. The fractured surface of neat PP (Figure 10(a)) is relatively smooth, representing typical brittle failure $[22,23]$. For $\mathrm{SiO}_{2} / \mathrm{PP}$ composites (Figure 10(b)), the fracture near the notch tip is still characterized by brittle damage although the size of the smooth area is reduced. In contrast, the fractured surface of $\mathrm{SiO}_{2}-\mathrm{g}$-PBA/PP composites shows a ductile failure near the notch zone (Figure 10(c)). Since the TEM observation indicates that small agglomerates of $\mathrm{SiO}_{2}$-g-PBA were drawn and dispersed in the matrix at an angle with the injection direction, it can be inferred that the grafted nano-silica might induce plastic deformation of the matrix surrounding the particles near the notch and have a pinning effect in the case of crack propagation [14], hindering crack growth and probably inducing multiple crazing. As a result, the $\mathrm{SiO}_{2}$-g-PBA/PP composites have acquired high impact resistance.

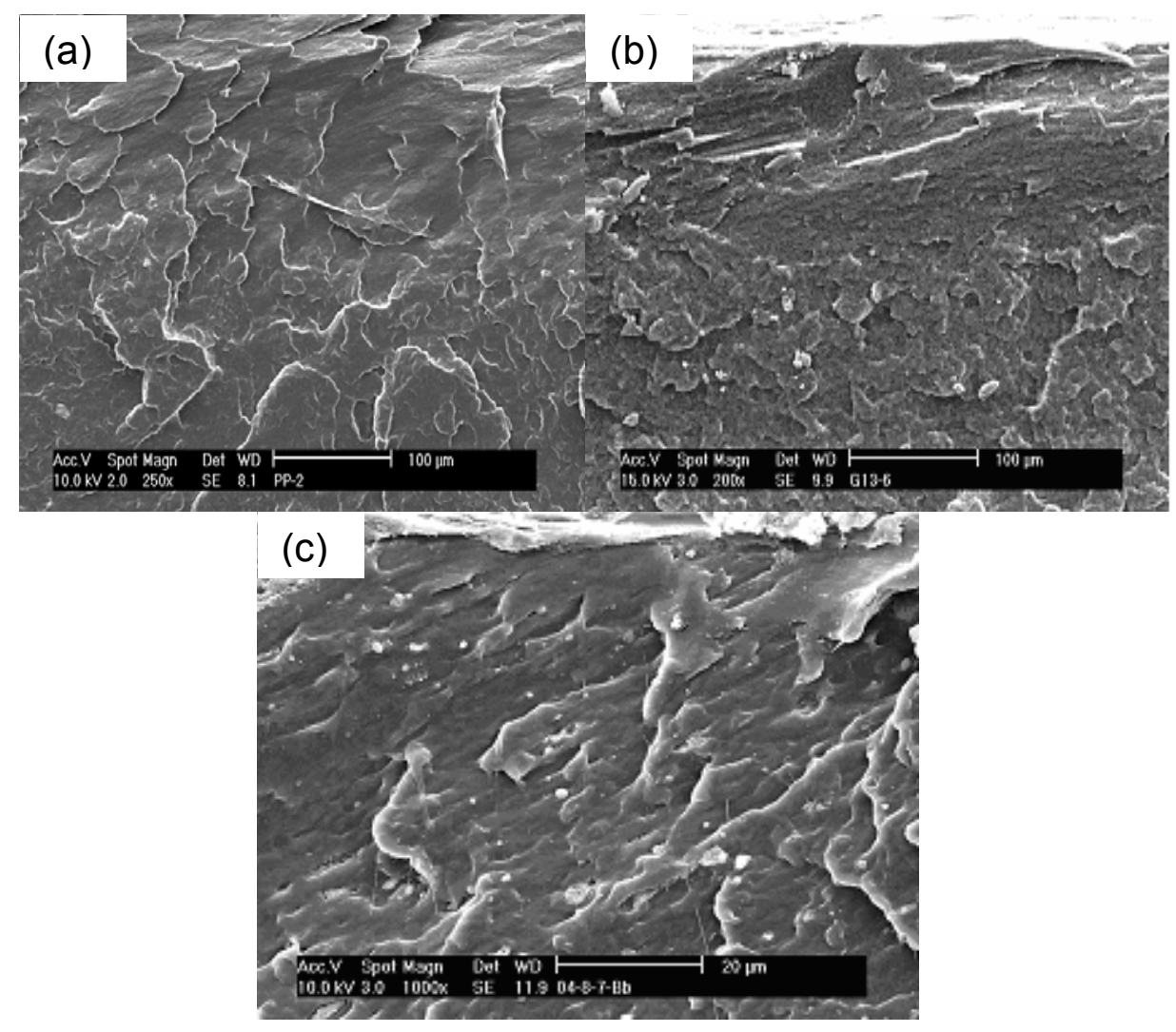

Fig. 10. SEM micrographs of impact fracture surface near the notch zone of (a) neat $\mathrm{PP}$, (b) $\mathrm{SiO}_{2}$ as-received/PP (content of nano- $\mathrm{SiO}_{2}=1.30 \mathrm{vol} \%$ ), and (c) $\mathrm{SiO}_{2}-\mathrm{g}$ $\mathrm{PBA} / \mathrm{PP}$ (content of nano-SiO $\mathrm{S}_{2}=1.36 \mathrm{vol} \%$ ). 


\section{Conclusions}

The technical route proposed in the current work is proved to be feasible for fabricating polymer composites with inorganic nanoparticles. Both reinforcing and toughening effects of nano-silica on PP can be brought into play by graft modification of the nanoparticles during melt compounding. It is confirmed that PBA is covalently attached to the surface of nano-silica using the proposed approach. Since the in-situ graft polymerization is carried out in association with the melt mixing, much finer nanoparticle agglomerates with more homogeneous distribution are obtained. Besides, filler/matrix interaction is enhanced accordingly.

Crystallization of PP composites is favoured owing to the nucleation effect of the nano-silica. Studies on crystalline morphology and dynamic mechanical property of the nanocomposites imply that most nano-silica might be distributed in the amorphous phase of the matrix and act as physical crosslinking sites. Morphologic observation reveals that grafted nano-silica agglomerates are deformed with injection-induced flow of the matrix forming "drawn patterns" at an angle with the injection direction. The microstructure might have facilitated plastic deformation of the matrix around the nano-fillers when the composites were subjected to applied force.

\section{Experimental}

Commodity isotactic PP homopolymer H1500 (Hyundai Petrochemical Co. Ltd., South Korea) having melting flow index (MI) of $11.5 \mathrm{~g} / 10 \mathrm{~min}\left(2.16 \mathrm{~kg}\right.$ at $\left.230{ }^{\circ} \mathrm{C}\right)$, fumed silica Aerosil 200 (Degussa Co., Germany, average particle size $12 \mathrm{~nm}$ and a specific surface area $200 \mathrm{~m}^{2} / \mathrm{g}$ ) were used in this experiment. Silane coupling agent, Y-methacryloxypropyl trimethoxy silane (trade-name: $\mathrm{KH}-570$, Chenguang Co., China) was chosen to pre-treat the fumed silica. Butyl acrylate (BA), commercially available was used directly for grafting reaction. Azobisisobutyronitrile (AIBN) was used as initiator.

The silica was preheated at $120^{\circ} \mathrm{C}$ under vacuum for $8 \mathrm{~h}$ to eliminate any possible absorbed water on the surface. Then the mixture of a certain amount of silica, KH570 and toluene solvent were ultrasonically vibrated for $30 \mathrm{~min}$. The pretreatment of silica was carried out in toluene at reflux temperature with stirring for $10 \mathrm{~h}$ under $\mathrm{N}_{2}$ atmosphere. For chemical analysis, some pretreated silica was recovered by centrifugation, washed for three times with toluene, and extracted by ethanol in a Soxhlet apparatus for $24 \mathrm{~h}$ to remove excess silane coupling agent, finally dried under vacuum at $40{ }^{\circ} \mathrm{C}$ for $48 \mathrm{~h}$, then at $100{ }^{\circ} \mathrm{C}$ for $1 \mathrm{~h}$.

Controlled amount of the pretreated silica, BA monomer and initiator were grounded in a planetary ball miller at $250 \mathrm{rpm}$ for $1 \mathrm{~h}$ at room temperature, and then mixed with PP. The mixture was melt compounded in the mixer of a torque rheometer (Haake Rheocord $300 p$ ) at suitable temperature, time and rotation speed, producing concentrated batches. For chemical analysis, the in-situ graft modified nano-silica should be separated from the nanocomposites. For this purpose, the crushed products were packed in copper nets (200 mesh) and extracted by xylene for $48 \mathrm{~h}$ to remove $\mathrm{PP}$ and homopolymerized poly(butyl acrylate) (PBA), finally dried under vacuum for $48 \mathrm{~h}$ at $50^{\circ} \mathrm{C}$, and then for $1 \mathrm{~h}$ at $100^{\circ} \mathrm{C}$.

The weight increase of nano-silica due to the presence of silane or grafting polymer was determined by a thermogravimetric analyzer (Netzsch TG 209) under a nitrogen flow at a heating rate of $10{ }^{\circ} \mathrm{C} / \mathrm{min}$. The recorded TGA thermograms are shown in 
Figure 11. FTIR (Bruker Equinox 55) and XPS (VG ESCALAB MK-II) were utilized to study structural changes in the silica surface before and after melt compounding.

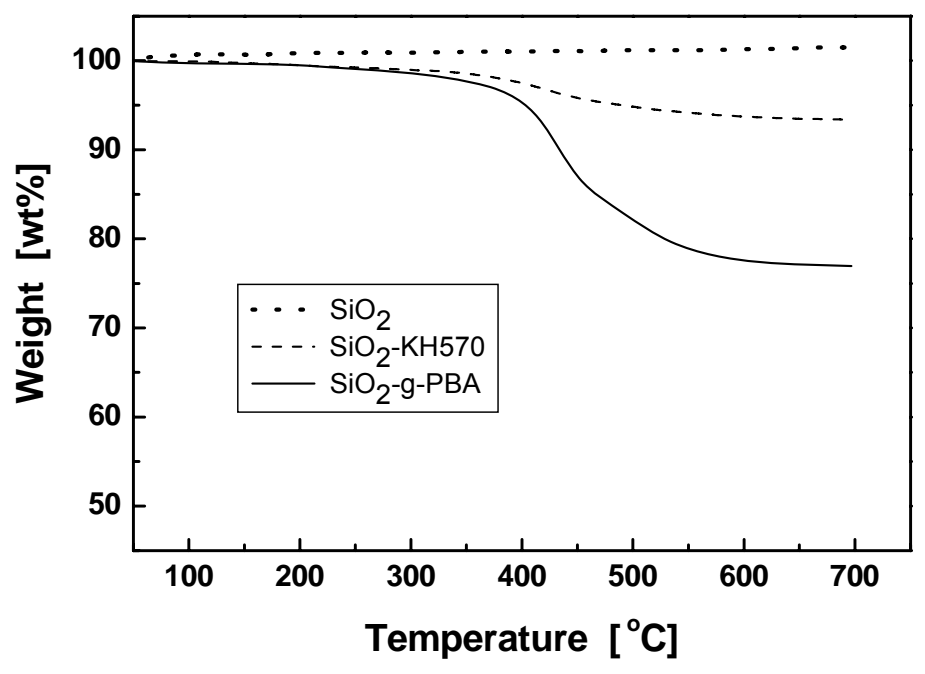

Fig. 11. TGA thermograms of nano-silica and the treated versions. The weight increase of the nanoparticles were determined by the weight changes at $700{ }^{\circ} \mathrm{C}$.

The concentrated batches were diluted into desired concentrations in the mixer of the torque rheometer to prepare nano-silica/PP composites. Then the compounds were broken up and injection molded into standard bar for mechanical tests with a vertical injection molding machine (Y-350) at $190{ }^{\circ} \mathrm{C}$. Tensile tests were carried out on a universal testing machine (Hounsfied H1OKS) at a crosshead speed of $5 \mathrm{~mm} / \mathrm{min}$ for Young's modulus and $50 \mathrm{~mm} / \mathrm{min}$ for tensile strength on ASTM D638-98. Advanced pendulum impact device (ATLAS) was used to determine the notched Charpy impact strength at a rate of $3.8 \mathrm{~m} / \mathrm{s}$ according to ISO 179-2. The dimensions of the specimens were $80 \times 10 \times 4 \mathrm{~mm}^{3}$, which were notched with an automatic sample notcher (ASN). The initial crack length was $2 \mathrm{~mm}$ and the span was $40 \mathrm{~mm}$ [12].

DSC (TA MDSC2910) was used to test non-isothermal melting and crystallization behaviour of $\mathrm{PP}$ and its nanocomposites. Both heating and cooling rates were 10 ${ }^{\circ} \mathrm{C} / \mathrm{min}$. DMA (TA DMA 2980) was conducted with a dual cantilever clamp in nitrogen atmosphere. The test frequency was $1 \mathrm{~Hz}$ and the test temperature was raised from $120{ }^{\circ} \mathrm{C}$ to $120{ }^{\circ} \mathrm{C}$ at a rate of $3^{\circ} \mathrm{C} / \mathrm{min}$.

For examining crystalline structure, the nanocomposites were pressed between glass plates at $180{ }^{\circ} \mathrm{C}$, cooled to room temperature and observed by a polarizing microscope (Orthoplan Pol). Ultrathin sections of the nanocomposites perpendicular and parallel to the injection direction of impact bars were investigated by TEM (JEM$2010 \mathrm{HR})$ ). Fractured surfaces of the nanocomposites after impact tests were checked by SEM (JEOL-5400).

\section{Acknowledgements}

The authors are grateful for the support of National Natural Science Foundation of China (Grant: 50473019), Natural Science Foundation of Guangdong, China (Grants: 
2004A10702001, 2005A10702001 and 5003267), the Science and Technology Department of Guangzhou, China (Grant: 2004Z3-D2061) and Guangdong Economic \& Trade Commission, China (Grant: 20040112).

\section{References}

[1] Bounor-Legare, V.; Angelloz, C.; Blanc, P.; Cassagnau, P.; Michel, A. Polymer. 2004, 45, 1485.

[2] Ruan, W. Q.; Zhang, M. Q.; Rong, M. Z.; Friedrich, K. J. Mater. Sci. 2004, 39, 3475 .

[3] Jana, S. C.; Jain, S. Polymer 2001, 42, 6897.

[4] Ruan, W. H.; Zhang, M. Q.; Rong, M. Z.; Friedrich, K. Polym. Polym. Compos. 2004, 12, 1257.

[5] Bikiarisa, D. N.; Vassilioua A.; Pavlidoub, E.; Karayannidis, G. P. Eur. Polym. J. 2005, 41, 1965.

[6] Pegoretti, A.; Dorigato, A.; Penati, A. Express Polym. Lett. 2007, 1, 123.

[7] Liu, Y. Q.; Kontopoulou M. Polymer 2006, 47, 7731.

[8] Tsubokawa, N.; Kobayashi, M.; Ogasawara, T. Progr. Org. Coat. 1999, 36, 39.

[9] Gunko, V. M.; Vorionin, E. F.; Pakhlov, E. M. Colloid. Surface A. 2000, 166, 187.

[10] Rong, M. Z.; Zhang, M. Q.; Zheng, Y. X.; Zeng, H. M.; Walter R.; Friedrich K. J. Mater. Sci. Lett. 2000, 19, 1159.

[11] Cai, L. F.; Huang, X. B.; Rong, M. Z.; Ruan, W. H.; Zhang, M. Q. Polymer 2006, $47,7043$.

[12] Cai, L. F.; Mai, Y. L.; Rong, M. Z.; Ruan, W. H.; Zhang, M. Q. Express Polym. Lett. 2007, 1, 2.

[13] Zhou, H. J.; Zhang, M. Q.; Rong, M. Z.; Friedrich, K. J. Mater. Sci. 2006, 41, 5767.

[14] Hayashi, S.; Fujiki, K.; Tsubokawa, N. React. Funct. Polym. 2000, 46, 193.

[15] Sondi, I.; Fedynyshyn, T. H.; Sinta, R.; Matijevic, E. Langmuir, 2000, 16, 9032.

[16] Long Y.; Shanks, R. A. J. Appl. Polym. Sci. 1996, 62, 639.

[17] Rybnikar, F. J. Appl. Polym. Sci. 1989, 38, 1479.

[18] Billmeyer, F. W. Textbook of Polymer Science. Wiley-Interscience. New York 1971.

[19] Nitta, K. H.; Asuka, K.; Liu, B. P.; Terano, M. Polymer 2006, 47, 6457.

[20] Papageorgiou, G. Z.; Achilias, D. S.; Bikiaris, D. N.; Karayannidis, G. P. Thermo. Acta 2005, 427, 117 .

[21] Zeng, H. M.; Rong, M. Z.; Zhang, M. Q. Polym. Bull. 1998, 2, 1. [in Chinese]

[22] Ferrer-Balas, D.; Maspoch, M. L.; Mai, Y. W. Polymer 2002, 43, 3083.

[23] Chen, H.B.; Karger-Kocsis, J.; Wu, J. S.; Varga J. Polymer 2002, 43, 6506. 